\title{
EL DERECHO A LA VIVIENDA EN EUROPA: DEBERES POSITIVOS Y DERECHOS EXIGIBLES (SEGÚN LA JURISPRUDENCIA DEL TRIBUNAL EUROPEO DE DERECHOS HUMANOS)
}

PADRAIC KENNA 
I. INTRODUCCIÓN. II. LOS DERECHOS DE CARÁCTER NEGATIVO EN EUROPA COMO PUNTO DE PARTIDA. III. EL MARCO DEL ESTADO CONTEMPORÁNEO. IV. EL CONVENIO EUROPEO Y LOS DERECHOS POSITIVOS: 1. El derecho a un proceso debido (artículo 6). 2. El respeto de la vida privada y familiar. 3. La prohibición de tratos inhumanos o degradantes (artículo 3). V. CONCLUSIÓN. 


\title{
EL DERECHO A LA VIVIENDA EN EUROPA: DEBERES POSITIVOS Y DERECHOS EXIGIBLES (SEGÚN LA JURISPRUDENCIA DEL TRIBUNAL EUROPEO DE DERECHOS HUMANOS $)^{1}$
}

\author{
POR \\ PADRAIC KENNA \\ Profesor en la Facultad de Derecho de la National University of Ireland, \\ Galway (Irlanda)
}

\section{INTRODUCCIÓN}

El Tribunal Europeo de Derechos Humanos (en adelante, el Tribunal o TEDH) ha desarrollado una perspectiva de los derechos humanos como obligaciones positivas que trasciende, hasta cierto punto, los conceptos liberales clásicos de los derechos humanos y constitucionales. Éstos siempre habían afectado a las limitaciones de las acciones del Estado, por lo que se imponía una revisión desde el contexto contemporáneo de los derechos humanos. El desarrollo legal, internacional y constitucional de los derechos ${ }^{2}$ incorpora en la actualidad

1 Traducción del original inglés por Daría Terrádez Salom (Universitat de València, España). Una versión del presente trabajo en inglés puede verse en el n. ${ }^{\circ}$ 2/2008 de la European Human Rights Law Review.

${ }^{2}$ Véase Anderson, G. W.: Constitutional rights after Globalization, Oxford, Hart, 2005.

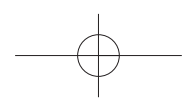


obligaciones positivas de los Estados respecto de la intervención y regulación de los actores privados y de las corporaciones nacionales e internacionales.

Mientras que el desarrollo de las políticas económicas y sociales de carácter neo-liberal, de alcance mundial, están provocando un retroceso de las fronteras del Estado, según la concepción de Hayek, respecto del bienestar de los ciudadanos, la jurisprudencia del Tribunal de Estrasburgo ${ }^{3}$ pone el acento en algunas obligaciones positivas que son una parte clave de las responsabilidades de éste. En efecto, Keir Starmer afirma que: "Las obligaciones positivas son el distintivo del Convenio Europeo de Derechos Humanos, lo que le singulariza respecto de otros instrumentos; especialmente de aquellos redactados antes de la Segunda Guerra Mundial.» ${ }^{4}$

\section{LOS DERECHOS DE CARÁCTER NEGATIVO EN EUROPA COMO PUNTO DE PARTIDA}

La noción liberal tradicional de los derechos comportaba una limitación de las injerencias por parte del Estado en la propiedad y en la acumulación de capital; de manera más específica, se limitaba la apropiación arbitraria haciendo va-

${ }^{3}$ El Convenio Europeo para la protección de los Derechos Humanos y de las Libertades Fundamentales recoge obligaciones positivas de los Estados respecto de determinados bloques de derechos, como la prevención frente a los tratos inhumanos y degradantes que se derivan de la indigencia en la que caen los solicitantes de asilo cuya demanda no ha tenido éxito — véase la sentencia de la House of Lords del Reino Unido recaída en el caso Regina (a instancia de Anufrijeva) vs. Secretario de Estado del Departamento de Interior (2003) UKHL 36; (2004) 1 A.C. 604- o la protección del hogar y de la vida familiar - Caso López Ostra vs España (1995) 20 European Human Rights Review 277. Los instrumentos internacionales de Naciones Unidas sobre derechos humanos exigen del Estado el respeto, protección y cumplimiento de sus obligaciones respecto de aquellos, teniendo en cuenta tanto lo que tradicionalmente se ha llamado obligaciones "positivas» como «negativas». La obligación de respeto de los Estados exige de éstos su abstención frente a injerencias en el goce de los derechos; la protección requiere emprender acciones para prevenir las violaciones de derechos por parte de terceros; el cumplimiento de dichas obligaciones exige de los estados la adopción de medidas legislativas, presupuestarias, judiciales y de otro tipo encaminadas a la plena realización de los derechos. Las obligaciones de los Estados se traducen en un compromiso que tiene como objetivo conceder un núcleo mínimo obligatorio respecto de los derechos afectados, sin discriminación alguna, así como la progresiva realización de éstos. Véase $\mathrm{KoCH}$, I. E.: «Dichotomies, Trichotomies or Waves of Duties?» (2005) 5(1) Human Rights Law Review 81. Véase también Doc. A/CONF 157/24 (1993) Vienna Declaration and Programme of Action, World Conference on Human Rights, Vienna.

4 Véase STARMER, K.: «Positive obligations Under the Convention», en Jowell Jowell, J., y Cooper, J. (eds.), Understanding Human Rights Principles, Oxford, Hart, 2001, p. 159. 
ler los poderes del monarca y de las entidades feudales. La libertad de expresión, el libre comercio y el derecho a la propiedad privada, la igualdad entre ciudadanos y gobernantes, la libertad frente a una detención arbitraria y la libre organización política representaban la piedra angular de los derechos civiles y políticos. La protección de estos derechos requería un importante desembolso por parte del Estado.

En efecto, tuvo que pasar mucho tiempo hasta que se reconoció legalmente el derecho al sufragio universal, y a sabiendas de que la igualdad formal puede enmascarar importantes desigualdades sociales y económicas. Los derechos se planteaban como obligaciones negativas de los Estados o del poder regio, y esta visión de los derechos tuvo su continuidad incluso después de haberse superado las formas políticas monárquicas o feudales por unas más democráticas. Es más, hemos de señalar que dicha visión continua vigente respecto de derechos como la vivienda, pese a los cambios que se han producido respecto de las funciones del Estado en los últimos cien años. Siguiendo con la propiedad liberal y los derechos constitucionales, el desarrollo del Estado de bienestar de posguerra y el reconocimiento por (nada más y nada menos) Roosevelt de que «la verdadera libertad individual no puede existir sin una seguridad económica e independencia» ${ }^{5}$ cambió la definición de los derechos y, más aún, la "libertad» en sentido amplio evolucionó hacia la noción de libertad en sentido estricto desde la necesidad y el temor.

Esta aproximación al Estado de Bienestar representó un cambio desde la visión liberal individualista, que sostenía que las personas eran libres de perseguir sus propios intereses en los mercados sin tener que sufrir ninguna injerencia por parte del Estado; y aquellos que no podían hacerlo únicamente se podían culpar a sí mismos. Existían, por supuesto, los "pobres meritorios», como las viudas o los huérfanos, ancianos o personas con discapacidades, con respecto de quienes desplegaba su actividad un cuantioso número de instituciones, muchas de ellas caritativas. Pero aquellos que eran "pobres indignos» debían recibir una «asistencia» estatal punitiva diseñada para obligarles a trabajar. No obstante, el desarrollo durante el siglo XX de los partidos políticos socialistas o de los sindicatos demostró que la pobreza y el desempleo eran auténticos problemas sociales y económicos y no fracasos personales, y que la responsabilidad colectiva podía remediar esas situaciones. ${ }^{6}$

5 Roosevelt, F. D.: 11. ${ }^{\circ}$ Mensaje Anual al Congreso (11 de enero de 1944), citado en Steiner, H. y AlstoN, P.: International Human Rights in Context, Oxford, OUP 2000, p. 243.

6 Vease IshaY, M.: «The socialist Contributions to Human Rights: An Overlooked Legacy» (2005) 9(22), International Journal of Human Rights 225. 
El Estado, siendo una expresión de la democracia política, se comprometió para proveer dicha asistencia. En algunos sectores intervino en los mercados liberales para asegurar resultados equitativos para las personas. Es más, se aceptó que el Estado debía asumir obligaciones positivas, contribuyendo al bienestar personal a través de los derechos sociales de los ciudadanos y de las personas en general. Marshall, en su obra "Citizenship and Social Class»", realiza una aproximación a la noción de los derechos sociales de los que deberían gozar los ciudadanos europeos:

«...La gama completa, desde un módico bienestar y seguridad económicos hasta el derecho a gozar de la totalidad de la herencia social y de la vida de un ser civilizado de acuerdo con los estándares vigentes.» ${ }^{8}$

De este modo, la democracia social ha cambiado la noción de derechos humanos, desde una obligación negativa del Estado que impide cualquier intervención de éste en la propiedad o en la posesión o acumulación de capital, hasta el reconocimiento de los derechos como obligaciones positivas que aseguran un bienestar individual para los ciudadanos.

Marshall sitúa este desarrollo en un contexto de ciudadanía extenso que incluye tres fases en los derechos de ciudadanía. Primero, los derechos civiles, abarcando la libertad individual, los derechos de propiedad, y la tutela judicial efectiva. En segundo lugar, los derechos políticos inherentes a una sociedad democrática. En tercer lugar, los derechos sociales de carácter socio-económico, incluidos el derecho a un bienestar económico, el derecho a compartir en beneficio de la sociedad y el derecho a vivir una vida digna de acuerdo con los estándares sociales vigentes. ${ }^{9}$ Para Marshall, los derechos sociales son obligaciones del Estado respecto de la sociedad entendida como un todo, antes que una serie de derechos individuales exigibles y justiciables. De este modo, en las sociedades capitalistas, la obligación del Estado es asegurarse de que los ciudadanos tienen la capacidad por sí mismos, o con ayuda, de encontrar una vivienda en el mercado a través de transacciones voluntarias. Esto se llevo a cabo gracias al acceso universal a los derechos en el Estado, y, a una escala más amplia, por las medidas correctivas que el Estado introdujo en áreas como la vivienda, la educación, la sanidad, la asistencia social y las pensiones. Este Es-

7 Marshall, T. H.: «Citizenship and Social Class», en Marshall, T. H., y Bottomore, T. (eds.), Citizenship and Social Class, Londres, Pluto Press, 1992, p.7.

${ }^{8}$ Marshall, T. H.: «Citizenship and Social Class» (1992), ya cit., p.7.

9 Véase ProcacCI, G.: «Poor Citizens: Social Citizenship versus individualisaion of Welfare», en CroucH, C., Eder, K., y TAmbini, D. (eds.): Citizenship, Markets and the State, Oxford, OUP, 2001. 
tado «social» europeo o posteriormente el Modelo Social Europeo ha sido descrito por Bauman:

«El 'Estado Social', la suprema gloria de la larga historia de la Europa democrática hasta su forma dominante, se encuentra hoy en retroceso. El Estado social basó su legitimidad y fundamentó su exigencia de lealtad y obediencia de sus ciudadanos en la promesa de defenderlos y de protegerlos del desempleo, la exclusión social y el rechazo así como contra las malas jugadas del destino - contra la consideración como un 'despojo humano' a causa de los errores individuales o la desgracia; en resumen, en la promesa de introducir certeza y seguridad en las vidas en las que el caos y las contingencias hubiesen sido el común denominador. Si un desventurado tropezaba y caía, habría alguien listo para cogerle de las manos y ayudarle a levantarse.» ${ }^{10}$

Pero también es importante analizar cómo las aproximaciones basadas en derechos crearon un mandato universal. Edgeworth lo describe de esta manera:

«La extensión de los derechos universales a la salud, educación y bienestar transformó de forma radical la relación entre los ciudadanos y el Estado: el Estado posee nuevas obligaciones y el ciudadano es el poseedor de un nuevo conjunto formal de derechos; ya no son sólo los derechos de participación en la actividad política y económica como cuando se produjo un avance con el nuevo grupo de derechos de ciudadanía, sino que aparece un derecho universal a un nivel mínimo de seguridad. El nuevo paquete de derechos desbanca los privilegios y la moderada discrecionalidad inherentes a la caprichosa y fortuita actividad de la caridad, la familia y la comunidad en su actuar como paliativo de la pobreza. Igualmente, debido a que estos derechos estaban enfocados a eliminar riesgos que afectan a una gran cantidad de ciudadanos, incluso a todos, no sólo a individuos, éstos gozan de un carácter más colectivo que individual...El Gobierno, pues, se convirtió en un gestor de riesgos, además de su condición de defensor de derechos individuales.» ${ }^{11}$

\section{EL MARCO DEL ESTADO CONTEMPORÁNEO}

Desde los años ochenta del siglo pasado, las corrientes neo-liberales han pretendido, en Europa occidental y Estados Unidos, que el Estado se inhiba, reduzca y privatice los servicios sociales, además de crear un vacío de Estado en

${ }^{10}$ Véase Bauman, Z. Wasted Lives, Modernity and its Outcasts, Cambridge, Polity Press, 2004 , p. 89.

11 Edgeworth, B.: Law, Modernity, Postmodernity, Alderhost, Ashgate, 2003, p.90.

(C) UNED. Revista de Derecho Político

N. ${ }^{\circ} 74$, enero-abril 2009, págs. 479-501 
áreas clave. ${ }^{12}$ Las nociones de independencia y de responsabilidad individual respecto de la vivienda han sufrido un retroceso.

«Un desarrollo paralelo es la reducción selectiva del nivel de disposiciones en materia de bienestar y un traspaso progresivo hacia el sector privado de las funciones tradicionales del estado respecto de aquél. Esta corriente general puede observarse también en el abandono progresivo del monopolio del Estado en materias relacionadas con el bienestar, y la correlativa asunción del control desde diversos sectores de la sociedad civil, sobre todo el mercado (el sector privado, la empresa), aunque, en cierto grado, también por el voluntariado, las asociaciones caritativas y las organizaciones religiosas. Igualmente las personas se desligan de los derechos universales, a favor de beneficios establecidos a cambio de un desembolso económico.»13

La aproximación de la nueva Tercera Vía en relación con los derechos de bienestar que implican responsabilidades sobre los receptores de ese bienestar para buscar trabajo o formación están ganando una aceptación generalizada. «No hay derechos sin responsabilidades» es una manifestación común, ${ }^{14}$ que desemboca en unos beneficios de bienestar condicionados, antes que en un incremento de responsabilidades respecto de los propietarios. El «republicanismo cívico» pone el acento en la "participación» como un derecho y como una obligación, aunque dicha participación pueda equivaler a trabajo forzado en los casos de trabajo mal pagado y de baja cualificación, como el sistema llamado work-fare ${ }^{15}$.El republicanismo cívico, crítico con el Estado de bienestar, acusándole de generar receptores de beneficios pasivos, se esfuerza en potenciar la responsabilidad personal y el empoderamiento.

Sin embargo, aún quedan numerosos cometidos respecto de los derechos sociales para que sean considerados como un beneficio para toda la sociedad, como un factor productivo y como una vía para erradicar la exclusión social. ${ }^{16}$

12 Véase Doherty, M., y otros: The Changing Role of the State: State Intervention in Welfare and Housing (Bruselas: FEANTSA, 2003); STRANGE, S.: "The Declining Authority of States», en The Global Transformation Reader, 2. ${ }^{\text {a }}$ edic. (Cambridge, Polity Press, 2003), capítulo 11; MARCUSE, P.: Neo-liberal Globalization and National Housing Policy, ponencia presentada en el Congreso de la European Network for Housing Research celebrado en Viena en 2002.

13 Edgeworth, B.: Law, Modernity, Postmodernity (2003), ya cit., p. 56.

14 Véase Giddens, A.: The third Way and its Critics, Londres, Polity Press, 2000, p.65.

15 Este tema se desarrolla de forma muy clara en Fredman, S.: «Human Rights Transformed: Positive Duties and Positive Rights», Oxford Legal Studies Research Paper No. 38/2006, Public Law, 2006, p. 498.

16 Véase la Comunicación de la Comisión al Consejo, al Parlamento Europeo, al Comité Económico y Social y al Comité de las Regiones Agenda de Política Social. Bruselas, 28 de junio de 
Estos objetivos son los que se encuentran detrás de muchas de las políticas sociales de la UE, tal y como se estableció en la agenda de Lisboa, y poseen unas implicaciones de gran relevancia respecto del enfoque de los derechos positivos ${ }^{17}$. No obstante, de los 18 indicadores de la exclusión social desarrollados en el año 2001, no hay ninguno específico en relación con la vivienda o con la carencia de ésta. ${ }^{18}$

Bengtsson, en su estudio sobre el corporativismo sueco en materia de vivienda, identifica un incremento por etapas en las disposiciones sobre la vivienda que culmina, desde 1990, en una fase de privatización o «desregulación». El autor establece que el derecho a una vivienda debe ser tratado en el contexto del mercado, con una pronta intervención en los derechos, a través de regulación y disposiciones normativas adoptadas por parte del Estado. ${ }^{19}$ El punto de vista de Bengtsson, siguiendo al de Marshall, es que en el contexto de un Estado de bienestar universal, la ley posee únicamente un papel limitado, definiendo y reforzando los derechos. Las políticas y la práctica, antes que la ley, son los principales ejes conducentes al acceso a la vivienda en esta aproximación hacia los derechos sociales universales. ${ }^{20}$ Es más, aún existe una larga serie de normas de Derecho privado relacionadas con la vivienda respecto de la propiedad, la igualdad de acceso, la protección de los consumidores, el Derecho de familia, el Derecho sucesorio, y los estándares en la vivienda. Esta situación, de hecho, entra en contradicción con la proclama de los tribunales al justificar su inactividad para reforzar los derechos socioeconómicos, basándose en la imprecisión y la va-

2000 COM (2000) 379 final; la Comunicación de la Comisión al Consejo, al Parlamento Europeo, al Comité Económico y Social y al Comité de las Regiones Agenda relativa a una consulta sobre una acción a nivel de la UE destinada a promover la inclusión activa de las personas más alejadas del mercado laboral, COM (2006) 44 final.

17 Véase Bernard, N.: «New Governance approach to Economic, Social and Cultural Rights», en HeRVEY, T., y KeNNER, J.: Economic and Social Rights in the EU Charter of Fundamental rights, Oxford, Hart, 2003; BORRAS, S., y JACOBSSON, K.: "The open method of co-ordination and new governance patterns in the EU» (2004) 11(2) Journal of European Public Policy 185.

${ }_{18}$ Véase el Informe sobre los indicadores en el ámbito de la pobreza y la exclusión social del Comité de protección social (Octubre 2001) http://ec.europa.eu/employment_social/news/2002/jan/report_ind_es.pdf (accesible desde el 24 de febrero de 2008). Véase también KenNA, P.: Housing Rights and Human Rights, Bruselas; FEANTSA, 2005, Cap. 4. Este estudio ha sido publicado en español por la Asociación PROHABITATGE de Barcelona como «Los derechos a la vivienda y los derechos humanos".

19 Véase Bengtsson, B.: Swedish Housing Corporatism-A Case of Path Dependence?, Comunicación presentada en el Congreso del ENHR, Julio de 2004, Cambridge, Inglaterra (Reino Unido).

20 Véase GoodCHILD, B.: «Implementing the Right to Housing in France: strengthening or Fragmenting the Welfare State?» (2003) 20 (2) Housing Theory and Society 86. 
guedad, los requerimientos de una acción positiva, la falta de competencia judicial, las restricciones presupuestarias, las doctrinas sobre separación de poderes, los despropósitos generados en las entidades territoriales y la irresponsabilidad del sector judicial. ${ }^{21}$

\section{EL CONVENIO EUROPEO Y LOS DERECHOS POSITIVOS}

Es en contradicción con el contexto analizado cuando surge la cuestión de dotar de más fuerza a las obligaciones positivas de los Estados, respecto de la aplicación de los derechos. El Convenio Europeo de Derechos Humanos contiene numerosos derechos negativos, provenientes de la tradición liberal, que protegen a los propietarios y a otras personas frente a las injerencias del Estado; sin embargo, desde 1979, el Tribunal ha reconocido la relación entre dos grupos de derechos. ${ }^{22}$ En el caso Airey vs Irlanda, el Tribunal Europeo de Derechos Humanos mantuvo lo siguiente:

«Mientras que el Convenio establece una serie de derechos de carácter esencialmente civil y político, algunos de ellos tienen implicaciones de naturaleza económica o social. El Tribunal considera por ello... que una interpretación del Convenio que pudiera extenderse hacia la esfera de los derechos sociales y económicos, no es un elemento decisivo contrario a dicha interpretación; no existe una separación drástica entre esa esfera y lo recogido por el Convenio.» ${ }^{23}$

Estas «implicaciones de naturaleza económica y social» pueden observarse a menudo en relación con los casos del artículo 1 del protocolo adicional al Convenio núm. 1, relativo a la protección de la propiedad. ${ }^{24}$ Efectivamente, la mayoría de los casos relacionados con este precepto versan sobre restitución de una propiedad indebidamente arrebatada por los Estados o una justa satisfacción económica en su lugar. Sin embargo, la obligación positiva de proteger los de146.

${ }^{21}$ Véase JHEelan, N.: «The Enforceability of Socio-Economic Rights» (2007) E.H.R.L.R.

22 Emberland afirma que el texto del Convenio está inspirado en el núcleo de valores del sistema capitalista y en el sistema de valores del estado liberal. Véase EMBERLAND, M.: The Human Rights of Companies: Exploring the Structure of ECHR Protection, Oxford, OUP, 2006, p.42.

23 Véase Airey vs. Irlanda (1979-1980) 2 E.H.R.R. 305 en [26]. Véase también Consejo de Europa: Overview of the case-law of European Court of Human Rights in social matters. Working Group on Social Rights GT-DH-SOC (2005)001. Estrasburgo, 22 de marzo de 2005.

${ }_{24}$ Véase James vs. United Kingdom (1986) 8 E.H.R.R. 123; Broniowski vs. Poland (2005) 40 E.H.R.R. 21. Véase también Art. 6 sobre el derecho a un proceso equitativo, o Art. 11 sobre la libertad de reunión y asociación. 
rechos sobre la propiedad privada, se traducen a su vez en obligaciones positivas limitadas para prevenir la destrucción de casas y otras cuestiones relacionadas, ya que el reconocimiento de los derechos posesorios ha conocido una expansión nada desdeñable. ${ }^{25}$ En cualquier caso, una proporción considerable de casos inadmitidos a trámite tratan derechos de carácter socio-económico y, por supuesto, la posibilidad de acceso, por parte de demandantes con pretensiones relacionadas con derechos de dichas características, a cualquier tribunal de justicia. En efecto, incluso ante la instancia jurisdiccional europea sigue siendo una limitación difícil de superar el hacer valer este tipo de derechos relacionados con el acceso y disfrute de los bienes relacionados con la vivienda.

No obstante, resulta importante recordar que el caso James vs. Reino Uni$\mathrm{do}^{26}$, el caso clásico sobre derechos de propiedad, respaldó la expropiación total de una propiedad privada a favor de derechos garantizados por ley, para obtener la plena posesión a muy bajo coste, por parte de los inquilinos. Por lo tanto, el Convenio puede amparar derechos relativos a la vivienda si se interpreta de una forma dinámica y constructiva. ${ }^{27} \mathrm{El}$ concepto de posesiones incluye, además de un derecho a una garantía social, ${ }^{28}$ un derecho a obtener un beneficio de la propiedad arrendada (es decir, ingresos no derivados de los pagos) como parte del pago de las rentas por parte de los arrendatarios. ${ }^{29} \mathrm{La}$ reciente sentencia recaída en el caso Hutten-Czapska vs. Polonia ${ }^{30}$ refleja una evolución de la jurisprudencia del TEDH a favor de unos mayores derechos para los propietarios, superando los derechos de los arrendatarios a una seguridad durante el arrendamiento y a la regulación de las rentas, desarrollados en la posguerra europea.

Existen numerosos e interesantes desarrollos jurisprudenciales relacionados con las obligaciones positivas, si bien el Tribunal permanece cauteloso en esta área. ${ }^{31}$ La doctrina relacionada con las obligaciones de carácter positivo exige a

25 Véase Oneryildiz vs. Turkey [GC] (2005) 41 E.H.R.R. 20.

26 James vs. United Kingdom (1986) 8 E.H.R.R. 123.

27 Véase Consejo de Europa: Overview of the case-law of European Court of Human Rights in social matters (2005).

28 Véase Gaygusuz vs. Austria (1997) 23 E.H.R.R. 364. En este caso el derecho a la asistencia de emergencia — en la medida en que se establece en la legislación aplicable — es un derecho de base pecuniaria según el art. 1 del Protocolo n. ${ }^{\circ} 1$.

29 Véase Hutten-Czapska vs. Poland (2006) 45 E.H.R.R. 4. La Gran Sala (comprobar) perfiló su postura en este caso con respecto a otros precedentes, como Spadea and Scalabrino vs. Italy (1996) 21 E.H.R.R. 482, o Mellacher vs. Austria (1996) 12 E.H.R.R. 391.

${ }^{30}$ Hutten-Czapska vs. Poland (2006) 45 E.H.R.R. 4.

31 Véase Mowbray, A.: Human Rights Law in Perspective: The Development of Positive Obligations under the European Convention on Human Rights, London, Sweet \& Maxwell, 2004, Cap. 9.

(C) UNED. Revista de Derecho Político 
los Estados miembros proteger a los individuos de las amenazas contra los derechos establecidos en el Convenio o ayudarles con el fin de obtener el goce pleno de esos derechos. Su base legal, en el articulado del Convenio, puede ser explícita o implícita. El Tribunal ha mejorado los deberes positivos expresos del estado para asegurar las garantías a un proceso debido, establecidas en el artículo 6. Por otra parte, el Tribunal ha deducido específicas obligaciones de carácter positivo, implícitas en los artículos 8 a 11 y 14, y un deber de llevar a cabo una investigación efectiva en el marco de los artículos 2, 3, 5 y 13. Con el fin de sistematizar la introducción de estas obligaciones implícitas, el Tribunal ha invocado dos principios generales: primero, la obligación general de los Estados miembros, establecida por el artículo 1, de reconocer a toda persona dependiente de su jurisdicción los derechos y libertades reconocidos en el Convenio; en segundo lugar, el principio de una interpretación efectiva, que requiere dotar a los derechos establecidos en el Convenio de un sentido práctico, amplio y pleno. El último principio encuentra una especificación alternativa, estableciendo que los derechos reconocidos en el Convenio deben ser garantizados no de una forma teórica o ilusoria, sino de una manera práctica y efectiva. ${ }^{32}$ Por consiguiente, el Tribunal ha declarado que existen obligaciones positivas implícitas en los artículos 2, 3, 5, 6, 8, 9, 10, 11, 13 y $14 .{ }^{33}$ Dichas obligaciones resultan más precisas cuando el Estado posee un control pleno sobre la situación de la persona, o cuando la persona no puede hacer valer los derechos establecidos en el Convenio por sí misma. ${ }^{34}$

\section{El derecho a un proceso debido (artículo 6)}

Los derechos relacionados con la vivienda han sido interpretados por el Tribunal en gran parte como derechos civiles o derechos de propiedad. Por ello, se hace necesario, cuando tratamos la carencia de una vivienda, una audiencia pública y justa y otros requisitos procedimentales tal y como han sido desarrollados en el artículo 6 del CEDH. ${ }^{35} \mathrm{La}$ falta de un procedimiento posesorio abreviado en casos relacionados con la vivienda, fue tratado por el Tribunal

32 Véase Airey vs. Irlanda (1979-1980) 2 E.H.R.R. 305.

33 Véase Mowbray, A.: Human Rights Law in Perspective, op. cit.

${ }^{34}$ Véase Mole, N.: Book review [2004] E.H.R.L.R. 601.

${ }^{35} \mathrm{El}$ artí. 6 del CEDH establece que: «Toda persona tiene derecho a que su causa sea oída equitativa, públicamente y dentro de un plazo razonable por un tribunal independiente e imparcial, establecido por la ley, que decidirá los litigios sobre sus derechos y obligaciones de carácter civil o sobre el fundamento de cualquier acusación en material penal dirigida contra ella.» 
en el asunto Connors vs. Reino Unido en $2004 .{ }^{36}$ En este caso, el Tribunal Europeo de Estrasburgo declaró que el desahucio del reclamante no fue ejecutado bajo ninguna garantía procedimental, a saber sin el debido razonamiento legal que justificara una interferencia de dichas características en sus derechos. ${ }^{37} \mathrm{El}$ Tribunal sostuvo que la existencia de garantías procedimentales resulta de una vital importancia en cuanto a la evaluación de la proporcionalidad de dicha interferencia. La necesidad de un procedimiento legal de desahucio rápido y el poder para ejecutarlo: «Sin la carga de establecer unas razones que puedan someterse al juicio de un tribunal independiente, asi como el fondo del asunto, no ha sido debidamente acreditada y no responde a ningún objetivo especifico..1 ${ }^{38}$

En relación con el artículo 6, el Tribunal sostuvo que «no hubo igualdad de armas y al reclamante se le denegó un acceso efectivo al Tribunal para poder recurrir esa grave interferencia en su hogar y su familia». ${ }^{39}$

\section{El respeto de la vida privada y familiar}

El artículo 8 protege el derecho al respeto del domicilio y de la vida privada y familiar de las personas. Se establece un derecho al acceso, a la ocupación y al goce pacífico del domicilio. Hasta ahora, tal y como apunta Fox, el valor de la vivienda como un fenómeno social, psicológico, cultural y emocional ha sido ampliamente reconocido en otras disciplinas, pero dicho valor no ha sido introducido en el terreno legal, donde proponer que la vivienda pueda tener un sentido más allá de la estructura física de la casa o el valor material que representa, continua presentando dificultades conceptuales ${ }^{40}$. Domicilio es un concepto autónomo independientemente de la clasificación que se le dé en la normativa nacional. ${ }^{41}$ El concepto de domicilio no se reduce a la morada o demás tierras o pertenencias del propietario, lo que se habita o se posee legalmente. ${ }^{42}$ Todos los procedimientos relacionados con la tenencia de una casa deben someterse a lo estipulado en el artículo $8 .{ }^{43}$ Aunque sea posible la aplicación del ar-

${ }^{36}$ Connors vs. United Kingdom (2004) 40 E.H.R.R. 9.

37 Connors (2004) 40 E.H.R.R. 9 en [95].

38 Connors (2004) 40 E.H.R.R. 9 en [94].

39 Connors (2004) 40 E.H.R.R. 9 en [102].

40 Véase FOX, L.: Conceptualising Home, Oxford, Hart, 2007.

41 Véase Chapman vs. United Kingdom (2001) 33 E.H.R.R. 18.

${ }^{42}$ Véase Qazi vs. Harrow LBC [2003] UKHL 43; [2004] 1 A.C. 983; Sheffield City Council vs. Smart [2002] EWCA Civ 4; [2002] H.L.R. 34; Buckley vs. United Kingdom (1996) 23 E.H.R.R. 101; O'Rourke vs. United Kingdom (App. N. $39022 / 97$ ), fallo de 26 de junio de 2001.

43 Lambeth LBC vs Howard (2001) EWCA Civ. 468; [2001] 33 H.L.R. 58. 
tículo 8, este, en relación con una injerencia legal en la propiedad, no queda satisfecho si la legislación no consagra un derecho tipificado como tal a favor del propietario si se demuestra el término del arrendamiento.

En el caso Connors vs. Reino Unido ${ }^{44} \mathrm{el}$ Tribunal consideró que una injerencia en el hogar, dentro del contexto del artículo 8, puede ser considerada como «necesaria en una sociedad democrática» y perseguir un fin legítimo únicamente si responde a una "necesidad social imperiosa» $y$, en particular, si es proporcionada al fin legítimo perseguido ${ }^{45}$. A este respecto, el «margen de apreciación" se deja a las autoridades nacionales, que conocen mejor que cualquier tribunal internacional, las necesidades y condiciones locales. Sin embargo, cuando derechos clave o que protejan la intimidad, como el derecho al respeto de la propia vivienda, entran en juego, el margen de de apreciación es reducido:

«Este margen variará dependiendo del derecho del Convenio controvertido, su importancia para la persona y la naturaleza de las actividades que se hayan restringido, así como el objetivo de dichas restricciones. El margen tenderá a ser más reducido cuando el derecho en cuestión sea crucial para el goce efectivo de derechos relacionados con la intimidad o sean derechos clave (véase, por ejemplo, Dudgeon vs. Reino Unido, sentencia del 22 de octubre de 1981, Series A n.o 45, p.21 párrafo 52; Gillow vs. Reino Unido, sentencia del 24 de noviembre de 1986, Series A, n.o 104, párrafo 55).." ${ }^{46}$

Habiéndose hallado una violación del artículo 8, el Tribunal sostuvo que el desahucio del demandante no se realizó con las adecuadas garantías procedimentales, especialmente con aquella que exige un razonamiento correcto para justificar una injerencia grave en sus derechos. Debido a esto, no se pudo estimar como justificado por «una imperiosa necesidad social» o proporcionada al fin legítimo que se perseguía.

En relación con el artículo 8, las obligaciones positivas del Estado respecto para garantizar el derecho del reclamante al respeto de su vida privada y familiar, ha sido puesto de relieve en numerosos casos recientemente. En el caso Hatton vs Reino Unido ${ }^{47}$ la contaminación acústica proveniente de los vuelos nocturnos fue considerado como una injerencia en su vida privada y familiar, aunque se justificara por el bienestar económico del país. En el caso López-Ostra vs España ${ }^{48}$ y Guerra vs. Italia ${ }^{49}$ la obligación positiva de las autoridades locales de controlar las

\footnotetext{
${ }^{44}$ Connors (2004) 40 E.H.R.R. 9.

45 Connors (2004) 40 E.H.R.R. 9 [81].

46 Connors (2004) 40 E.H.R.R. 9 [81].

47 (2003) 34 E.H.R.R. 1.

48 (1994) 20 E.H.R.R. 277.

49 (1998) 26 E.H.R.R. 357.
} 
molestias y el riesgo originado por la ubicación de una planta de tratamiento de basura cerca de una industria de curtidos, y los efectos de las emisiones toxicas procedentes de una industria química respectivamente, constituyó una infracción por parte del Estado al no cumplir con sus obligaciones positivas que garantizaran el respeto de la vida privada y familiar reconocido en el artículo 8:

«Si se analiza la cuestión en términos de obligaciones positivas del Estado tomar medidas razonables y apropiadas para garantizar los derechos de la recurrente del apartado primero del artículo $8,[\ldots]$, o en términos de una «interferencia del poder público" para justificarlo de acuerdo al apartado 2, [...] los principios aplicables son muy semejantes. En ambos contextos debe tenerse cuidado de lograr un equilibrio justo entre los intereses del individuo y de la comunidad, gozando en todo caso el Estado de un cierto margen de apreciación.» ${ }^{50}$

En el caso Moreno-Gómez vs. España ${ }^{51}$ la inactividad por parte del Estado para paliar o reducir debidamente el ruido nocturno proveniente de las salas de fiestas, resultó un incumplimiento de las obligaciones positivas garantes del derecho de la reclamante al respeto de su vida privada y familiar, establecido en el artículo 8. En el caso Fadeyeva vs. Rusia ${ }^{52}$ se dictaminó a favor de una mujer rusa que había sufrido la violación de sus derechos, protegidos por el artículo 8, ya que el gobierno había incumplido sus obligaciones al no prevenir o regular adecuadamente la contaminación ambiental procedente de una planta de tratamiento de acero que afectaba negativamente a su calidad de vida y le causó una mayor predisposición a padecer enfermedades.

En el caso Zehnalova vs. República Checa $^{53}$ las obligaciones positivas, emanadas del artículo 8, que pesaban sobre una autoridad local fueron tomadas en consideración de nuevo. La autoridad local no acató los requerimientos técnicos de accesibilidad a los edificios públicos para las personas con movilidad reducida. El Tribunal subrayó que las obligaciones positivas de las autoridades locales parten del deber de velar por la aplicación de la ley. En este caso, el artículo 8 establece que la autoridad competente en la materia debe garantizar a las personas con movilidad reducida el acceso y el uso de los edificios públicos. Pero un incumplimiento del precepto únicamente se podría declarar cuando hubiera una estrecha relación entre la falta de acceso y las necesidades particulares de los individuos que denuncian una vulneración de su vida privada. Esto se aplicaría

\footnotetext{
50 (1994) 20 E.H.R.R. 27 en [51].

51 (2004) 41 E.H.R.R. 40.

52 (2005) 45 E.H.R.R. 10.

53 (Demanda N. ${ }^{\circ}$ 38621/97), decisión sobre la admisibilidad de 14 de mayo de 2002.
} 
cuando se diera un incumplimiento de las obligaciones positivas y la consecuencia fuera la injerencia en el derecho del reclamante al desarrollo de su personalidad y a la posibilidad de establecer y mantener relaciones con el mundo exterior $^{54}$.

El precedente del caso en el cual entra en consideración el artículo 8, Botta vs. Italia, ${ }^{55}$ (donde la demanda tampoco prosperó en cuanto al fondo), estableció que el Estado tiene una obligación positiva cuyo fin es garantizar a las personas con discapacidad el goce, en la medida de lo posible, de una vida privada y familiar normal:

«La vida privada, desde la perspectiva del Tribunal, prevé la integridad física y psicológica de la persona; la garantía proporcionada por el artículo 8 del Convenio tiene como objetivo básico el asegurar el desarrollo, sin ningún tipo de injerencia externa, de la personalidad de cada individuo en sus relaciones con otros seres humanos (véase, por analogía, el caso Niemietz vs. Alemania e 16 de diciembre de 1992, Serie A, n.o251-B, p.33, párrafo 29)..$^{5}$

En el caso concreto la reclamación del demandante no venía motivada por una injerencia positiva, sino por la falta de acción del Estado. Aunque el núcleo del artículo 8 radique en proteger al individuo frente a injerencias arbitrarias por parte de las autoridades públicas, no debe únicamente compeler al Estado a abstenerse de realizar ese tipo de injerencias: además de esa obligación de carácter negativo, deberían considerarse obligaciones positivas inherentes al respeto efectivo de la vida privada y familiar. Estas obligaciones deberían prever la adopción de medidas tendentes a garantizar el respeto de la vida privada, incluso en la esfera de las relaciones entre los particulares (véase el caso Xe Y vs. Holanda de 26 de marzo de 1985, Serie A, n. ${ }^{\circ 299-B, ~ p .61, ~ p a ́ r r a f o ~ 38) . ~ S i n ~ e m b a r g o, ~ e l ~ c o n-~}$ cepto de respeto no está claramente definido. Para determinar si dicha obligación existe o no, debemos tener en cuenta que medie un equilibrio justo entre el interés general y los intereses de los individuos, si bien el Estado posee, en todo caso, un margen de apreciación.» ${ }^{57}$

El artículo 8 no exige al Estado el facilitar una vivienda a cada ciudadano, pero existen determinadas circunstancias en las cuales se podría deducir dicha exigencia del Convenio. En el caso Marzari vs Italia ${ }^{58}$ el demandante, con una discapacidad severa, consideró que el apartamento que había alquilado no se en-

\footnotetext{
${ }^{54}$ En este caso la parte demandante no alegó dicha relación y la demanda se inadmitió.

55 (1998) 26 E.H.R.R. 241.

56 (1998) 26 E.H.R.R. 241 en [32].

57 (1998) 26 E.H.R.R. 241 en [33].

58 (2000) 30 E.H.R.R. CD218.
} 
contraba adaptado de forma adecuada a sus necesidades, por lo que dejó de pagar el alquiler hasta que dichas adaptaciones se llevaran a cabo. Si bien el artículo 8 no garantiza la resolución por parte del Estado de los problemas relacionados con la vivienda, el que el Estado rehúse la asistencia a una persona con una discapacidad grave puede incardinarse en lo regulado por el artículo 8 debido al impacto negativo de esta decisión en la vida privada de la persona. ${ }^{59}$

«El Tribunal considera que, si bien el artículo 8 no garantiza la resolución por parte del Estado de los problemas relacionados con la vivienda, el que el Estado rehúse la asistencia a una persona con una discapacidad grave puede incardinarse en lo regulado por el artículo 8 debido al impacto negativo de esta decisión en la vida privada de la persona. El Tribunal recuerda que, si bien la esencia del artículo 8 es la protección de la persona frente a injerencias arbitrarias de las autoridades públicas, no significa que únicamente el Estado deba abstenerse: además de este compromiso de carácter negativo, deben de considerarse obligaciones de carácter positivo inherentes al respeto efectivo de la vida privada. Un Estado tiene este tipo de obligaciones cuando existe una relación directa e inmediata entre las medidas solicitadas por el demandante y su vida privada más reciente. ${ }^{60}$

Sin embargo, en relación con la carencia de vivienda, el Tribunal rehuyó la posibilidad de deducir un derecho a la vivienda en el artículo 8. En el caso Chapman vs. Reino Unido ${ }^{61}$ el Tribunal sostuvo que el artículo 8 no otorga un derecho a ser provisto de vivienda, y que esto era un asunto político y no jurídico.

En el caso Codona vs. Reino Unido ${ }^{62}$, el recurrente — una familia gitanaocupó un solar contraviniendo las regulaciones urbanísticas. La madre sostuvo que la ejecución del desalojo sin ofrecerle un lugar alternativo (se le ofreció una casa) violaba los artículos 8 y 14, resultando una injerencia en su vida nómada. El Tribunal afirmó que podría darse, en el artículo 8, una obligación de carácter positivo en el sentido de facilitar su modo de vida nómada, pero dicha obligación únicamente podría hacerse valer si existiera un espacio adecuado, y la autoridad lo denegara. La Alcaldía del municipio, sin embargo, no se encontraba sometida a dicha obligación positiva de facilitar un alojamiento sin «ladrillos y cemento», pues no había ningún sitio disponible.

Sin embargo, las acciones de las autoridades estatales deben respetar las obligaciones positivas emanadas de los derechos del Convenio. En el caso Moldavan y otros vs. Rumania ${ }^{63}, 13$ casas gitanas pertenecientes a los recurrentes fue-

59 (1999) 28 E.H.R.R. CD175 en [179].

60 (1999) 28 E.H.R.R. CD175 en [179].

61 (2001) 33 E.H.R.R. 18.

62 (Demanda N. ${ }^{\circ 485 / 05)}$, decisión sobre la admisibilidad de 7 de febrero de 2006.

63 Moldovan vs. Romania (2005) 44 E.H.R.R. 16. 
ron destruidas y éstos denunciaron la participación de agentes estatales. $\mathrm{Al}$ invocar los artículos 3 y 8 del CEDH, los recurrentes se quejaron de que, tras la destrucción de sus casas, no pudieron disfrutar más de sus hogares y tuvieron que subsistir en condiciones miserables y hacinamiento. Los recurrentes afirmaban que el Gobierno rumano tenía una obligación positiva emanada de los artículos 3 y 8 debiendo compensarles suficientemente para restablecer sus anteriores condiciones de vida. Afirmaban asimismo que el incumplimiento por parte del Gobierno de sus obligaciones positivas había tenido serias consecuencias sobre familias con niños pequeños, y personas mayores, obligándoles a vivir en sótanos, gallineros, establos, chabolas quemadas, o bien obligándoles a trasladarse a casas de amigos o familiares, por lo que en situaciones de hacinamiento, las enfermedades hacían pronto su aparición. El Tribunal, resaltando los principios generales aplicables al caso, sostuvo:

«El Tribunal ha sostenido consecuentemente que, si bien la obligación emanada del artículo 8 es esencialmente proteger a la persona frente a injerencias arbitrarias realizadas por las autoridades públicas, no es una mera obligación de abstenerse de realizar dichas actuaciones. Se debe, además de asumir ese carácter negativo, respetar unas obligaciones de carácter positivo que conlleven un respeto efectivo del hogar y de la vida privada y familiar. Dichas obligaciones deben convertirse en medidas diseñadas para garantizar el respeto de esos derechos incluso en la esfera privada... ${ }^{64}$

Más adelante, el Tribunal sostuvo:

«Independientemente del carácter del análisis adoptado —obligación positiva o injerencia- los principios aplicables en relación con su justificación mediante lo establecido en el artículo 8.2 son, en términos generales, similares... En ambos contextos, se debe tener en cuenta un equilibrio justo entre los intereses de las personas y el interés de la comunidad. En ambas situaciones el Estado posee un determinado margen de apreciación a la hora de establecer medidas que garanticen la efectividad del Convenio... Es más, incluso en relación con las obligaciones positivas que se derivan del artículo 8.1, ante la salvaguardia de ese equilibrio justo, los principios desarrollados en el artículo 8.2 deben ser observados. ${ }^{65}$

Dichos principios fueron de aplicación en el caso del Sr. Moldovan y los otros recurrentes, por lo que el Tribunal apreció la violación del artículo 3. Además dictaminó que se produjo una grave violación del artículo 8 al haber existido una continua perturbación debido a un incumplimiento permanente

${ }^{64}$ Moldovan vs. Romania (2005) 44 E.H.R.R. 16 en [93].
65 Moldovan vs. Romania (2005) 44 E.H.R.R. 16 en [97]. 
por parte de las autoridades de poner fin a las injerencias en el derecho de los demandantes. Respecto de las condiciones de vida, el Tribunal argumentó:

«Además se considera que, debido a las condiciones de vida de los demandantes en los últimos diez años, especialmente las graves condiciones de hacinamiento y de falta de higiene y sus efectos negativos sobre su salud y bienestar, añadiéndose a ello la duración del procedimiento durante el cual han tenido que vivir en dichas condiciones y la actitud en general de las autoridades, todo ello ha debido de producir un gran sufrimiento psíquico, lo que ha actuado en detrimento de su dignidad, despertando en ellos sentimientos tales como el de humillación y degradación. El Tribunal ha sostenido consecuentemente que, si bien la obligación emanada del artículo 8 es esencialmente proteger a la persona frente a injerencias arbitrarias realizadas por las autoridades públicas, no es una mera obligación de abstenerse de realizar dichas actuaciones. Se debe, además de asumir ese carácter negativo, respetar unas obligaciones de carácter positivo que conlleven un respeto efectivo del hogar y de la vida privada y familiar. Dichas obligaciones deben convertirse en medidas diseñadas para garantizar el respeto de esos derechos incluso en la esfera privada... ${ }^{66}$

El futuro desarrollo de la protección establecida por el artículo 8 en relación con el respeto a la privacidad del hogar, debe abarcar nuevas situaciones. Harris destaca lo siguiente:

«El [Tribunal europeo de Derechos Humanos] es reacio a la elaboración de una declaración de derechos. En relación con el artículo 8, semejante proceder ha sido una ventaja así como un claro retroceso ya que un particular tiene más dificultades hasta llegar al Tribunal, tal y como demuestra la profusa jurisprudencia a este respecto. La ventaja es que el Tribunal ha podido tomar en consideración las circunstancias y condiciones cambiantes sin estar sujeto a un marco teórico rígido..." ${ }^{67}$

Ello no obstante, parece que exista una cierta indiferencia por parte del Tribunal a recurrir a la jurisprudencia desarrollada a partir de la Carta Social Europea, la cual, a través del Comité Europeo de Derechos Sociales, viene estableciendo variadas interpretaciones de los derechos relacionados con la vivienda y definiciones legales de éstos.

${ }^{66}$ Moldovan vs. Romania (2005) 44 E.H.R.R. 16 en [110].

${ }^{67}$ Harris, D. J., et al.: Law of the European Convention on Human Rights, London, Butterworths, 1995, p. 353.

(C) UNED. Revista de Derecho Político

N. ${ }^{\circ}$ 74, enero-abril 2009, págs. 479-501

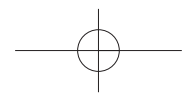




\section{La prohibición de tratos inhumanos o degradantes (artículo 3)}

Las obligaciones positivas derivadas del artículo 3 que conminan a los Estados a prohibir cualquier trato inhumano y degradante, están siendo interpretadas en casos relacionados con la carencia de vivienda y los deberes del Estado al respecto.

La Cámara de los Lores en Inglaterra en el caso Limbuela, un hito jurisprudencial, tuvo en cuenta las obligaciones positivas del Estado, derivadas del artículo 3, para no amparar a los solicitantes de asilo ${ }^{68}$. La cuestión radicaba en determinar cuándo aparece el deber del Estado de prohibir tratos inhumanos y degradantes. Lord Bingham sostuvo que:

«La respuesta debe ser en mi opinión la siguiente: cuando se de dentro de una apreciación justa y objetiva de todos los hechos relevantes y circunstancias que un solo reclamante afronte una posibilidad inminente de sufrir seriamente $o$ materialmente agravada por la denegación de cobijo, comida o la más básica necesidad vital. Numerosos factores afectan a este juicio, incluyendo la edad, el sexo (el género), la salud mental y física y las condiciones en que esa persona se encuentra, cualquier facilidad o fuentes de apoyo accesibles por parte del reclamante, las condiciones atmosféricas y el periodo del año y el tiempo durante el cual el reclamante ha sufrido o puede sufrir de privación.»"

Carnwath L.J. subrayó en el tribunal de apelación que:

«La cuestión planteada por el recurso, en su forma más cruda, consiste en dilucidar hasta qué nivel de abyecta indigencia deben dichos individuos degradarse para que su sufrimiento o humillación alcance el «mínimo nivel de severidad» para que equivalga a un "trato inhumano y degradante» establecido por el artículo 3 del Convenio Europeo de Derechos Humanos.» ${ }^{70}$

Las obligaciones positivas de los Estados son más estrictas cuando sus propias políticas no respetan los derechos del Convenio.

«La necesidad de un juicio resulta evidente para determinar en un supuesto dado si el tratamiento o el castigo han alcanzado el grado de seriedad necesario. Es en ese momento cuando el Tribunal debe considerar, teniendo en cuenta todos los hechos, si la prueba ha sido superada. Pero sería un error pensar que el análisis, que hubiese dado lugar a la calificación de los tratos como inhumanos y de-

${ }^{68}$ R. (a instancia de Limbuela) vs. Secretary of State for the Home Department [2005] UKHL 66; [2006] 1 A.C. 396.

69 R. (a instancia de Limbuela) [2005] UKHL 66; [2006] 1 A.C. 396 en [8].

70 R. (a instancia de Limbuela) [2004] EWCA Civ 540; [2004] Q.B. 1440 en [84] 
gradantes, es más minucioso cuando esos tratos provienen de una actuación proveniente de la legítima política del gobierno, tal y como lo expone Laws L.J. Esto supondría introducir, por la puerta trasera, la prohibición absoluta de consideraciones de proporcionalidad. Éstas son relevantes cuando la obligación de hacer algo se encuentra expresada de forma tácita en el Convenio. En este caso la obligación del Estado no es absoluta e incondicional. Pero la proporcionalidad, que otorga un margen de apreciación a los Estados, no ha lugar cuando la conducta de la que es directamente responsable tiene como resultado un trato inhumano o degradante o un castigo. La obligación de abstenerse de realizar dicha conducta es absoluta.» ${ }^{71}$

En un reciente caso inglés, se ha decretado la indemnización por daños al amparo del Acta de Derechos Humanos del Reino Unido de 1998, contra una autoridad local en relación con la dotación de alejamiento inadecuado. En $R$. (a instancia de Bernard) vs. Enfield LBC ${ }^{72}$ (Enfield London Bourough Council) la Corte Suprema falló que las autoridades habían incurrido en incumplimiento, de forma ilegal e incompatible con el artículo 8 , durante más de dos años al no dotar a una familia con un alojamiento adecuado. La madre, que sufría de discapacidad severa y debía usar una silla de ruedas, fue acogida temporalmente por las autoridades en un alojamiento que comportó su confinamiento en el salón. La conducta de las autoridades no sólo comprometió el artículo 8, sino que además lo conculcó, al condenar a los reclamantes a unas condiciones de vida que hacían virtualmente imposible que pudieran disfrutar de una vida privada o familiar dotada de sentido según lo establecido por el artículo mencionado. La pretensión de la conculcación del artículo 3 en relación con el padecimiento de tratos inhumanos y degradantes no se tuvo en cuenta al estimarse que la falta de atención por parte de la autoridad competente no tenía como objetivo el infligir deliberadamente dicho padecimiento. La sentencia recoge lo establecido en el caso otta $^{73}$ y argumenta lo siguiente:

«El respeto de la vida privada y familiar no obliga al Estado a facilitar a cada uno de sus ciudadanos un alojamiento. Sin embargo, aquellos ciudadanos cuya situación pueda tener cabida en el artículo 21 (del Acta del Reino Unido) pertenecen a un grupo particularmente vulnerable. Se deben de regular determinadas medidas (a través de los servicios sociales de la comunidad) para que puedan, en la medida de lo posible, gozar de una vida privada y familiar normal. El incumplimiento por parte del ayuntamiento significó una clara falta de respeto hacia la

${ }^{71}$ R. (a instancia de Limbuela) [2004] EWCA Civ 540; [2004] Q.B. 1440 en [55]

72 [2002] EWCH admin. 2282; [2003] H.R.L.R. 4.

73 Botta vs. Italy (1998) 26 E.H.R.R. 241.

(C) UNED. Revista de Derecho Político

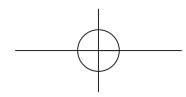


vida privada y familiar de los reclamantes. Se les condenó a vivir en condiciones que impedían llevar una vida privada y familiar digna de acuerdo con lo establecido por el artículo 8.»

\section{CONCLUSIÓN}

Tal y como hemos podido observar, el Convenio, en ocasiones, establece obligaciones de carácter positivo. La cuestión no es sino cual es el mínimo esencial de derechos que deben protegerse y, dentro del amplio y complejo sistema de vivienda europeo, que efectividad tiene este enfoque.

De un extremo a otro de Europa, la política de vivienda se ha convertido en un elemento que favorece y camina parejo al papel fundamental del mercado inmobiliario, al que se le ha otorgado dicho papel fundamental debido a la construcción y asignación de viviendas nuevas y de alquiler. Este sistema encuentra su sustento en una variada gama de mecanismos de administración, desde el registro de los títulos hasta los procedimientos de financiación hipotecaria, pasando por el planeamiento, los estándares y los controles regulatorios, así como una amplia selección de incentivos fiscales. La liberalización del mercado financiero ha desarrollado un patrón en Europa, mediante la desaparición de los límites de los intereses, la relajación de los controles efectuados sobre los créditos y la desaparición de las restricciones de entrada en el mercado hipotecario ${ }^{74}$. La cantidad total en referencia al mercado de financiación de vivienda a finales de 2003 era de más de 4,2 trillones de dólares. Esta cantidad es el doble de la suma de hace 10 años y la media de crecimiento durante estos diez años ha sido de un $8 \%$. Es una parte importante de la economía europea, elevándose aproximadamente a un $42 \%$ del PIB $^{75}$. La protección del consumidor padece un ritmo de crecimiento lento a causa de la armonización de los mercados.

Además de lo anterior, para poder definir el contenido esencial de los derechos positivos en relación con la vivienda, ésta debe integrar todos los componentes del mercado inmobiliario, como el control sobre el suelo de los terratenientes, el poder de las corporaciones financieras cuyo objetivo son los mercados inmobiliarios equitativos repartidos por Europa, los promotores que ostentan monopolios, la conformidad con los patrones actuales, y el papel y el relativo poder de otros agentes en el mercado inmobiliario. De manera creciente, en este

74 Véase Banco Central Europeo: Structural Factors in the EU Housing Markets, Frankfurt, ECB, 2003, p. 42.

75 International Union for Housing Finance, World Congress 2004, Conference Report, p. 16. 
contexto mercantil (ya se trate de mercado libre o de un ámbito más social), los derechos respecto de la vivienda pueden también comprender la protección de los derechos del consumidor, en términos generales, financiación hipotecaria, y contratos con cláusulas abusivas en los contratos de alquiler o compra. ${ }^{76}$

Mientras que el Tribunal Europeo de Derechos Humanos ha ido desarrollando algunas obligaciones de carácter positivo en relación con el disfrute del derecho a la vivienda por todas las personas, el Convenio también «ofrece una protección amplia para las entidades empresariales, como las sociedades, además de las organizaciones sin ánimo de lucro o las personas naturales» ${ }^{77}$. Emberland destaca que el Tribunal no observa los litigios societarios con recelo, y en el terreno de la vivienda las implicaciones de los casos como el asunto HuttenCzapska vs Polonia ${ }^{78}$ alentará numerosos litigios de este tipo ${ }^{79}$.

Todavía, en toda Europa, quedan numerosos grupos de personas que no gozan del mínimo esencial de protección de sus derechos relativos a la vivienda, como los gitanos, mujeres víctimas de violencia de género ${ }^{80}$, personas que padecen discapacidades, refugiados, inmigrantes, nacionales de terceros Estados, solicitantes de asilo, minorías nacionales y otros grupos socialmente excluidos, así como personas que se encuentran en el nivel más bajo del mercado laboral. A esto se añade que los Estados están llevando los sistemas públicos de vivienda (incluyendo la vivienda social y protegida) hacia el sector privado, sociedades públicas o privadas o hacía enfoques de carácter mercantilista.

La pregunta de cómo el sistema de derechos humanos articulado en torno al TEDH con sus obligaciones positivas pueda interactuar o influir en los sistemas de vivienda en los Estados europeos continúa sin respuesta. El Tribunal aborda los derechos relacionados con la vivienda de forma oblicua, al obviar a su hermano del Consejo de Europa, el Comité de Derechos Sociales, un órgano que está desarrollando de manera regular la jurisprudencia sobre las obligaciones del Estado respecto de la materia que se ha analizado ${ }^{81}$. La no injerencia pasiva de

${ }^{76}$ Véase la Comunicación de la Comisión Estrategia para una politica de consumo 2000-2006, COM (2002) 208 final [2002] DOUE C137/2. Véase también la Directiva 93/13 sobre cláusulas abusivas en los contratos de consumo [1993] DOUE L95/29 y http://europa.eu.int/clab.

77 Véase Emberland, M.: The Human Rights of Companies, op.cit., p.3.

78 (2006) 45 E.H.R.R. 4.

79 Véase GREAR, A.:»Challenging Corporate 'Humanity': Legal Disembodiment, Embodiment and Human Rights" (2007) 7(3) Human Rights Law Review 511.

${ }^{80}$ Véase Paglione, G.: "Domestic Violence and Housing Rights: A Reinterpretation of the Right to Housing» (2006) 28 (1) Human Rights Quaterly 120.

${ }^{81}$ Véase Consejo de Europa, European Committee on Social Rights, European Social Charter (revised) Conclusions 2003 - Volume 1 (Bulgaria, France, Italy) (Strasbourg: Council of Eu- 
los Estados allá donde los derechos de las personas contenidos en el Convenio están en juego no es suficiente para garantizar que dichos derechos sean respetados. Las obligaciones positivas respecto de las personas deben situarse en un plano superior al de los intereses económicos. El Tribunal Europeo de Derechos Humanos tiene una extensa tarea por delante de perfeccionamiento de las obligaciones positivas sobre los derechos de vivienda que ya se apuntan en la jurisprudencia existente; no obstante, debería prestar más atención a la jurisprudencia, más fructífera, de su órgano judicial homólogo, el Comité Europeo de Derechos Sociales.

\author{
Title \\ HOUSING RIGHTS IN EUROPE: POSITIVE DUTIES AND \\ ENFORCEABLE RIGHTS (ACCORDING TO THE EUROPEAN \\ COURT OF HUMAN RIGHTS CASE LAW)
}

\title{
Sumario
}

I. INTRODUCCIÓN. II. LOS DERECHOS DE CARÁCTER NEGATIVO EN EUROPA COMO PUNTO DE PARTIDA. III. EL MARCO DEL ESTADO CONTEMPORÁNEO. IV. EL CONVENIO EUROPEO Y LOS DERECHOS POSITIVOS: 1. El derecho a un proceso debido (artículo 6). 2. El respeto de la vida privada y familiar. 3. La prohibición de tratos inhumanos o degradantes (artículo 3). V. CONCLUSIÓN.

\section{Summary}

I. INTRODUCTION. II. MOVING FROM NEGATIVE RIGHTS IN EUROPE. III. THE CONTEMPORARY STATE. IV. THE EUROPEAN CONVENTION AND POSITIVE RIGHTS: 1. Rights to a fair trial (Article 6). 2. Respect for private and family life (Article 8). 3. Prohibition of inhuman or degrading treatments (Article 3). V. CONCLUSION.

\section{Resumen}

El presente trabajo expone el desarrollo experimentado en la jurisprudencia del Tribunal Europeo de Derechos Humanos respecto de la

rope Publishing, October 2003). Consejo de Europa, European Committee on Social Rights, European Social Charter (revised) Conclusions 2003 - Volume 2 (Romania, Slovenia, Sweden) (Strasbourg: Council of Europe Publishing, October 2003); véase también European Committee on Social Rights: Digest of the Case Law, December 2006. 
perspectiva de los derechos humanos como obligaciones positivas en el contexto de la vivienda. En este sentido, se traza la evolución desde el concepto liberal tradicional de los derechos de carácter negativo, pasando por la influencia de los modelos de Estado de bienestar durante la posguerra, hasta el Estado contemporáneo, desde 1980. El estudio, cuyo eje viene constituido por los derechos de propiedad, se centra en la jurisprudencia del Tribunal Europeo de Derechos Humanos. Se destaca el articulado del Convenio Europeo de Derechos Humanos, centrándose en los artículos, 3, 6 y 8, así como en las obligaciones positivas que de ellos se derivan. El autor presta especial atención a determinados artículos del Convenio Europeo de Derechos Humanos sobre los que el Tribunal ha fijado obligaciones positivas. El autor concluye que el tribunal tiene aún una larga tarea respecto de la redefinición de las obligaciones positivas referentes a los derechos de vivienda, debiéndose basar en la valiosa jurisprudencia del Consejo de Europa.

\begin{abstract}
This paper discusses the European Court of Human Rights' development of a human rights perspective on positive obligations in the context of housing. Traces the move from traditional liberal concepts of negative rights, the influence of post-war welfare state models and the contemporary state since the 1980s. Examines, with emphasis on property rights, the jurisprudence of the European Court of Human Rights. Considers salient articles of the European Convention on Human Rights 1950, focusing on Art.3, Art.6 and Art.8 and the implied positive obligations. The author concludes that the Court has much work to do in refining positive housing rights obligations, but might find valuable jurisprudence within the Council of Europe.
\end{abstract}

\title{
Palabras clave
}

Vivienda - Obligaciones positivas - Derechos de propiedad - Comité Europeo de Derechos Sociales

\section{Keywords}

Housing - Positive obligations - Property rights - European Committee of Social Rights

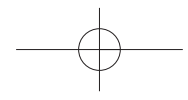

